\title{
THE DETERMINATION OF SULPHUR IN IRON AND STEEL.
}

BY William A. NOYes aNd L. LEgLie Helmer.

Received July $1, \mathbf{s}$ or.

\begin{abstract}
$A$ LTHOUGH very many methods for the determination of $A$ sulphur in iron have been proposed, ${ }^{2}$ none of those in common use is altogether satisfactory. None of the evolution methods will give correct results with some irons, unless the evolved gases are led through a heated tube to convert organic compounds of sulphur into hydrogen sulphide. ${ }^{3}$ The aqua regia method sometimes leaves sulphur in the residue ${ }^{4}$ and the precipitation of barium sulphate in the presence of iron, which it usually involves, is always objectionable. The method which we propose obviates at least a part of these difficulties.
\end{abstract}

\section{SOLUTION.}

We tried at first various methods of solution, including solution in concentrated nitric acid and hydrochloric acid, as given by Blair in his "Chemical Analysis of Iron," in concentrated nitric acid with a little potassium chlorate toward the end of the solution; in hydrochloric acid and potassium chlorate; in bromine and water; and in dilute nitric acid with a little potassium bromide and an excess of potassium chlorate. The last two methods were finally adopted as the most satisfactory.

Solution in Bromine and Water. - The bromine must, of course, be free from sulphur. Ours was purified by mixing with a little dry sodium carbonate and distilling from a plain retort. Put $200 \mathrm{cc}$. of water and $8 \mathrm{cc}$. of bromine in a flask and add 5 grams of the iron or steel in portions, cooling after each addition. Solution takes place readily. When it is complete, boil for a moment to expel the slight excess of bromine. Filter, wash the residue, add to it some sodium carbonate and burn the filter in a platinum crucible, using an alcohol lamp, and completing the oxidation by the addition of some potassium nitrate. Dissolve the residue in water, filter, acidify with hydrochloric acid, add $5 \mathrm{cc}$. of barium chloride solution, digest till the precipitate settles readily and

1 The work here described formed the basis of a thesis for the degree of Bachelor of Science at the Rose Polytechnic Institute. The preliminary work on the subject was done by $\mathrm{Mr}$. Herbert $\mathrm{F}$. Madison, of the class of 1900 .

2 See Bibliography by Brearley in Chem. News, 82, 281 (1900).

3 Phillips : This Journal, 17,891.

4 Blair: This Journal, 19, II4. 
determine as usual. ${ }^{1}$ Add three-fifths of the weight of barium sulphate found here to that obtained from the main solution. The main solution, containing ferric bromide, is to be precipitated as described below.

More sulphur is usually found in the residue by this process than by the solution in nitric acid and potassium chlorate, but it has the advantage that the solution can be filtered at once, while the solution in nitric acid clogs a filter so badly that evaporation to dryness is required.

2. Solution in Nitric Acid, Potassium Bromide and Potassium Chlorate.-Put into a flask $\mathrm{r} 2 \mathrm{O}$ cc. of dilute nitric acid (sp. gr. I. 20 , or I : 2 by volume) and I gram of potassium bromide. Add in portions, 5 grams of the iron mixed with 7 grams of potassium chlorate, cooling somewhat, if necessary. When the iron is dissolved, transfer to a flat porcelain dish and evaporate to dryness in such a manner that contact with the products of combustion of the gas is avoided. Dissolve the residue in concentrated hydrochloric acid, dilute, filter, and treat the residue as before, and the filtrate as directed below.

\section{PRECIPITATION.}

Put into a $500 \mathrm{cc}$. graduated flask I $30 \mathrm{cc}$. of ammonia (Io per cent.), and add the solution obtained by either method above. Make the volume up to $500 \mathrm{cc}$, mix thoroughly by pouring back and forth into a dry beaker, and filter through a dry filter. The filtrate must, of course, be strongly alkaline. Take $300 \mathrm{cc}$. of the filtrate and evaporate, in a wide beaker, to roo cc. During this evaporation contact with the products of combustion of illuminating gas must be avoided. We have used for the purpose a piece of stove-pipe flattened on one side and connected at one end with an elbow and upright piece to carry away the products of combustion. The hot steam plate of most iron and steel laboratories wotld be admirably adapted to this purpose. Add one drop of dilute hydrochloric acid (sp. gr. I.12) and ro cc. of barium chloride, digest hot till the precipitate settles quickly after stirring; filter, ignite and weigh as usual. The precipitate represents the amount of sulphur in 3 grams of the iron or steel.

To test the accuracy of the precipitation, seven determinations

I Dr. C. B. Dudley, who has kindly done some work with the bromine method, is of the opinion that the barium sulphate obtained from the residue requires purification by fusion with sodium carbonate, and it seems that this point requires further study. 
were made with solutions containing known amounts of sulphur. For the first three a low sulphur steel was dissolved in hydrochloric acid, the solution boiled, filtered, and oxidized to ferric iron with bromine. Two blanks, made with quantities of this solution representing 5 grams of iron, gave respectively 0.0001 and 0.0004 gram barium sulphate.

The fourth and fifth determinations were made with a solution obtained by dissolving 5 grams of steel No. I in water and bromine. The mean value for the sulphur in this steel, neglecting the residue, had been found to be 0.027 per cent. The sixth and seventh determinations were made with 5 grams of iron No. I, which contains, apart from the residne, 0.095 per cent. of sulphur. The extra sulphur for these experiments was added in the form of ferrous ammonium sulphate. The results are stated as percentages of the iron used, and indicate the accuracy to be expected in actual work, so far as this depends on the method of precipitation used.

\begin{tabular}{|c|c|c|}
\hline Sample. & $\begin{array}{l}\text { Sulphur } \\
\text { present. }\end{array}$ & $\begin{array}{l}\text { Sulphur } \\
\text { found. }\end{array}$ \\
\hline alphur-free iron $+\mathrm{Fe}\left(\mathrm{NH}_{4}\right)_{2}\left(\mathrm{SO}_{4}\right)_{2} \ldots \ldots \ldots$ & 0.0056 & 0.0050 \\
\hline Sulphur-free iron $+\mathrm{Fe}\left(\mathrm{NH}_{4}\right)_{2}\left(\mathrm{SO}_{4}\right)_{2} \ldots \ldots \ldots$ & 0.012 & $0.01 \mathrm{I}$ \\
\hline Sulphur-free iron $+\mathrm{Fe}\left(\mathrm{NH}_{4}\right)_{2}\left(\mathrm{SO}_{4}\right)_{2} \ldots \ldots \ldots$ & 0.016 & 0.016 \\
\hline Steel No. I $-\mathrm{Fe}\left(\mathrm{NH}_{4}\right)_{2}\left(\mathrm{SO}_{4}\right)_{2} \ldots \ldots \ldots \ldots \ldots$ & 0.129 & 0.129 \\
\hline Steel No. I $+\mathrm{Fe}\left(\mathrm{NH}_{4}\right)_{2}\left(\mathrm{SO}_{4}\right)_{2} \ldots \ldots \ldots \ldots \ldots$ & 0.234 & 0.211 \\
\hline Iron No. I $+\mathrm{Fe}\left(\mathrm{NH}_{4}\right)_{2}\left(\mathrm{SO}_{4}\right)_{2} \ldots \ldots \ldots \ldots \ldots$ & 0.490 & 0.500 \\
\hline Iron $\mathrm{No} . \mathrm{I}+\mathrm{Fe}\left(\mathrm{NH}_{4}\right)_{2}\left(\mathrm{SO}_{4}\right)_{2} \ldots \ldots \ldots \ldots \ldots$ & 0,689 & 0.679 \\
\hline
\end{tabular}

The advantages of this method of precipitation are that the precipitation is made with a solution free from iron, and that by the evaporation of the ammoniacal solution it becomes neutral, and by the addition of one drop of dilute hydrochloric acid a constant degree of acidity is secured. The results indicate that, even with very small amounts of sulphur, an accurate precipitation is secured in the presence of ammonium chloride or bromide.

To secure a uniform sample for use in testing the method, a considerable quantity of cast-iron drillings were ground to a fine powder in a heavy iron mill. Samples Nos. I and 2 were prepared in this way. Samples Nos. 3, 4, and 5 were ordinary drillings of iron used in making car wheels. Nos. 6 and 7 were samples of steel.

Determinations were made with sample No. I by Blair's gravimetric evolution method, using an alkaline solution of lead to 
absorb the hydrogen sulphide evolved; and by Blair's aqua regia method, precipitating the sulphuric acid in the presence of the iron. As will be seen below, the evolution method gives less than one-half of the sulphur actually present in this iron. Whether the irregular and low results obtained by the aqua regia method are due to a failure to secure a complete oxidation of the sulphur during solution, or to imperfect precipitation of barium sulphate in the acid iron solution, can not be known with certainty, but the results of the aqua regia method, combined with our method of precipitation, point rather to the first explanation as the true one. The following are the results with iron No, I :

Evolution method,
Blair.
0.044
0.049
0.044
0.042

\begin{tabular}{cc}
\multicolumn{2}{c}{$\begin{array}{c}\text { Aqua regia method, } \\
\text { Blair. }\end{array}$} \\
\hline 0.084 & 0.077 \\
0.080 & 0.068 \\
0.088 & 0.058 \\
$\ldots$. & $\ldots \ldots$
\end{tabular}

The following determinations were made with different methods of solution followed by precipitation of the iron with ammonia and determination of the sulphuric acid in an aliquot part of the filtrate.

\begin{tabular}{|c|c|c|c|c|c|}
\hline Sample. & $\begin{array}{c}200 \mathrm{cc}, \mathrm{H}_{2} \mathrm{O} \\
35 \mathrm{cc} \mathrm{HCl}(\mathrm{I}, 12), \\
7 \text { grams KClO }\end{array}$ & $\begin{array}{l}\text { Con, } \mathrm{HNO}_{3} \\
\text { with little } \\
\text { con. HCl, } \\
\text { Blair. }\end{array}$ & $\begin{array}{c}40 \mathrm{cc} \text {. con. } \mathrm{HNO}_{3} \\
\text { with } 1 / 2 \text { gramm } \\
\text { Kclo }\end{array}$ & 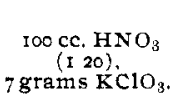 & $\begin{array}{c}200 \mathrm{cc} . \mathrm{H}_{2} \mathrm{O} \\
8 \mathrm{cc} . \mathrm{Br} .\end{array}$ \\
\hline Iron No, I. & 0.105 & 0.059 & 0.094 & 0.075 & 0.097 \\
\hline Iron No. I. & 0.041 & 0.074 & 0.097 & 0.084 & 0.095 \\
\hline Iron No. I. & 0.079 & 0.098 & 0.089 & 0.088 & 0.095 \\
\hline Iron No. I. & 0.077 & 0.031 & 0.087 & $\ldots$ & $\cdots$ \\
\hline Iron No. I. & 0.054 & $\ldots$ & 0.090 & $\ldots$ & $\ldots$ \\
\hline
\end{tabular}

The results indicate that the use of concentrated nitric acid with the addition of a little potassium chlorate, when solution is nearly complete, or the use of bromine and water, give the most concordant and, probably, the most accurate results. The first of these methods is accompanied by the evolution of large volumes of nitrogen peroxide and requires considerable time. Solution in dilute nitric acid (sp. gr. I. 2O) with potassium bromide and 7 grams of potassium chlorate is more rapid and gives satisfactory results.

In the following determinations the methods which have been described in detail were used. When the total sulphur is not given the solution was poured into the ammonia without previous 
filtration. Where the total sulphur is given, the solution in bromine was filtered and the sulphur in the residue determined, while the solution in nitric acid was evaporated to dryness, the residue dissolved in concentrated hydrochloric acid, diluted, filtered, and the sulphur in the residue determined.

\begin{tabular}{|c|c|c|c|c|}
\hline \multirow{2}{*}{ Sample. } & \multicolumn{2}{|c|}{$\begin{array}{c}200 \mathrm{cc} . \mathrm{H}_{2} \mathrm{O} \\
8 \mathrm{cc} \cdot \mathrm{Br} .\end{array}$} & \multicolumn{2}{|c|}{$\begin{array}{c}120 \mathrm{cc} . \mathrm{HNO}_{3}(\mathrm{I} .20), \\
\text { I gram } \mathrm{KBr} \\
7 \mathrm{grams} \mathrm{KClO} \\
\end{array}$} \\
\hline & $\begin{array}{l}\text { Soluble } \\
\text { sulphur. }\end{array}$ & $\begin{array}{c}\text { Total } \\
\text { sulphur. }\end{array}$ & $\begin{array}{l}\text { Soluble } \\
\text { sulphur. }\end{array}$ & $\begin{array}{c}\text { Total } \\
\text { sulphur. }\end{array}$ \\
\hline Iron No. I. & 0.097 & $\ldots$ & 0.084 & $\ldots$ \\
\hline Iron No. I. & 0.095 & $\cdots$ & 0.088 & $\cdots$ \\
\hline Iron No. I. & 0.095 & $\ldots$ & $0.09 I$ & $\cdots$ \\
\hline Iron No. I. & 0.085 & 0.106 & 0.088 & $\cdots$ \\
\hline Iron No. I. & 0.093 & 0.117 & 0.093 & 0.120 \\
\hline Iron No. I. & $\cdots$ & $\cdots$ & 0.083 & o. 106 \\
\hline Iron No. I. & $\cdots$ & $\cdots$ & 0.099 & 0.116 \\
\hline Iron No. I. & $\ldots$ & $\ldots$ & 0.095 & 0.107 \\
\hline Iron No. 2. & 0.068 & $0.09 \mathrm{I}$ & 0.088 & 0.099 \\
\hline Iron No. 2. & 0.070 & 0.092 & 0.086 & 0.095 \\
\hline Iron No. 3. & 0.129 & o. 155 & 0.157 & 0.159 \\
\hline Iron No. 3. & 0.129 & $0.14^{8}$ & 0.155 & 0.159 \\
\hline Iron No. 4 & $0 . I_{3}$ & 0.144 & 0.142 & 0.149 \\
\hline Iron No. 4. & 0.110 & 0.147 & $0.14 I$ & 0.149 \\
\hline Iron No. 5. & 0.075 & 0.095 & $0.08_{3}$ & 0.095 \\
\hline Iron No. 5. & 0.077 & 0.094 & 0.079 & 0.089 \\
\hline Steel No. 6. & 0.026 & $\cdots$ & $\cdots$ & $\cdots$ \\
\hline Steel No. 6. & 0.027 & $\cdots$ & $\cdots$ & $\cdots$ \\
\hline Steel No. 6. & 0.026 & $\cdots$ & $\cdots$ & $\cdots$ \\
\hline Steel No. 6. & 0.029 & $\cdots$ & $\cdots$ & $\cdots$ \\
\hline Steel No. 7. & 0.018 & 0.029 & 0.019 & 0.022 \\
\hline Steel No. 7 & 0.017 & 0.025 & 0.014 & 0.025 \\
\hline
\end{tabular}

The sulphur of the residue, after solution in bromine and water, varies from 0.015 to 0.037 per cent. with an average of 0.023 . The sulphur in the residue after solution in nitric acid, potassium bromide, and potassium chlorate, and evaporation, varies from 0.002 to 0.027 per cent. with an average of 0.012 . With iron of a given character, the sulphur in the residue will probably be found nearly uniform, so that the original solution can be precipitated at once with ammonia, without previous filtration, and a constant correction for the sulphur of the residue applied. When this is done, the method becomes, we think, more rapid than any gravimetric method now in use. 